\title{
THE PERFORMANCE OF BDS RELATIVE POSITIONING USAGE WITH REAL OBSERVATION DATA
}

\author{
A performance do BDS no posicionamento relativo usado com dados de \\ observações reais \\ XU TANG \\ XIUFENG HE \\ SAMUEL A. ANDAM-AKORFUL \\ Institute of Satellite Navigation and Spatial Information System \\ Hohai University, Nanjing, China \\ tang.gnss@gmail.com
}

\begin{abstract}
With the first phase of COMPASS/BeiDou-2 (BDS) completed, the assessment of positioning performance and the characterization of its system are analyzed and presented. Pseudo-range and carrier phase measurements modulated on B1 and B2 have been collected in Shanghai, from 00:00 to 24:00 on 28 December, 2012. Compared with GPS, visibility and measurement quality of BDS's GEO, IGSO and MEO satellites are analyzed. DOP during the whole orbital period is also analyzed the results demonstrate that BDS's HDOP is better than GPS's one, but VDOP opposite. Furthermore, the result of positioning is also presented and analyzed. Short baselines are estimated by standalone BDS and GPS's carrier phase measurement, respectively, using 48 segmentations of observations during a whole day ( 24 hours, each segmentation, is about 30 minutes observation). The analysis of static relative positioning demonstrates that BDS could achieve to millimeter level, corresponding to GPS. Kinematic result is produced by double differenced carrier phase observations with the ambiguities fixed under the constraint of precise short baseline.The result shows that the centimeter accuracy could be achieved. When comparing the results of kinematic baseline solutions, performance of BDS is worse than GPS on North and Up components, but oppositely on the component of East in the kinematic baseline processing.
\end{abstract}


Keywords: Global Positioning Navigation System; BDS; Navigation Satellite Constellation; Baseline Accuracy

\section{RESUMO}

Com a primeira fase do Sistema COMPASS/BeiDou-2 (BDS) finalizada, este trabalho analisa e apresenta uma avaliação do desempenho do posicionamento e caracterização do BDS. O principal objetivo deste trabalho é comparar o desempenho do BDS em relação ao GPS em termos de acurácia (posicionamento estático e cinemático), Diluição da Precisão (Dilution of Precision - DOP, i.e., HDOP e VDOP), e visibilidade e qualidade das medidas para os satélites GEO, IGSO e MEO do BDS. Para alcançar este objetivo, coletou-se as pseudodistâncias e medidas de fase da onda portadora, modulada em B1 e B2, em uma estação localizada em Xangai durante o período de 00:00 até 24:00 no dia 28 de dezembro de 2012. Estimou-se uma linha de base curta através de medidas de fase da onda portadora durante um período de 24 horas com 48 segmentos de observações (a duração de cada segmento foi de aproximadamente 30 minutos). Os resultados do posicionamento cinemático foram obtidos a partir da dupla diferença de fase com as ambiguidades fixadas através da injunção de uma linha de base curta (precisa). De forma geral, os resultados das analises do posicionamento relativo estático mostram que o BDS alcança uma acurácia ao nível do milímetro o que é equivalente ao GPS. No caso do posicionamento cinemático, uma acurácia centimétrica é alcançada mostrando que o desempenho do BDS é melhor para a componente este, entretanto, o contrário para as outras componentes, i.e., oeste e vertical. Assim, pode-se concluir que para um pior cenário, a acurácia do BDS coincide com a do GPS ao nível do centímetro. No entanto, mais experimentos devem ser conduzidos para avaliar a qualidade do BDS sobre a região da Ásia-Pacífico, e.g., Austrália.

Palavras-chave: Sistema de Navegação de Posicionamento Global; BDS; Constelação de Satélites de Navegação; Acurácia da Linha Base.

\section{INTRODUCTION}

The booming global navigation satellite systems of coming years, from America modernizing GPS, Russia refreshing GLONASS, the developing of Europe Galileo navigation system and the Chinese navigation system moving ahead from a regional navigation system (BeiDou-1) to a full constellation global navigation system (COMPASS/BeiDou-2/BDS), will cause numerous of new potential applications and researches. BDS is Chinese new satellite navigation system and its contribution for the GNSS communities is obvious. The application of GNSS will be more widely due to its special constellation and the communication capacity of BDS (CAO et al. 2008).

After the developed BeiDou-1 which is two-dimensional active positioning and provides coverage only over China, the developing BDS is global navigation system with the global scale coverage. With the first satellite named as M1 launched 
in 2007, BDS constellation began to deploy (Table 1). It should be mentioned that, BDS includes two phases. The first phase of BDS completed at the end of 2012, with 5 Geosynchronous Earth Orbit (GEO), 5 Inclined Geosynchronous Satellite Orbit (IGSO), and 4 Medium Earth Orbit (MEO) satellites operation (Figure 1).

Table 1 - BDS navigation system status (December 2012).

\begin{tabular}{l|l|l|c|c|c}
\hline Sat & PRN & Type & $\begin{array}{c}\text { Launch } \\
\text { time }\end{array}$ & Longitude & Latitude \\
\hline G1 & C01 & GEO & $2010 / 1 / 17$ & $140.07^{\circ} \mathrm{E}$ & \\
\hline G6 & C02 & GEO & $2012 / 10 / 25$ & $80.22^{\circ} \mathrm{E}$ & \\
\hline G3 & C03 & GEO & $2010 / 6 / 2$ & $110.56^{\circ} \mathrm{E}$ & \\
\hline G4 & C04 & GEO & $2010 / 11 / 1$ & $160.00^{\circ} \mathrm{E}$ & \\
\hline G5 & C05 & GEO & $2012 / 2 / 25$ & $58.65^{\circ} \mathrm{E}$ & \\
\hline I1 & C06 & IGSO & $2010 / 8 / 1$ & $104.63^{\circ} \mathrm{E}-136.05^{\circ} \mathrm{E}$ & $54.61^{\circ} \mathrm{S}-54.61^{\circ} \mathrm{N}$ \\
\hline I2 & C07 & IGSO & $2010 / 12 / 18$ & $102.60^{\circ} \mathrm{E}-134.13^{\circ} \mathrm{E}$ & $54.81^{\circ} \mathrm{S}-54.81^{\circ} \mathrm{N}$ \\
\hline I3 & C08 & IGSO & $2011 / 4 / 10$ & $100.49^{\circ} \mathrm{E}-133.82^{\circ} \mathrm{E}$ & $56.02^{\circ} \mathrm{S}-56.02^{\circ} \mathrm{N}$ \\
\hline I4 & C09 & IGSO & $2011 / 7 / 27$ & $80.12^{\circ} \mathrm{E}-111.79^{\circ} \mathrm{E}$ & $54.93^{\circ} \mathrm{S}-54.93^{\circ} \mathrm{N}$ \\
\hline I5 & C10 & IGEO & $2011 / 12 / 2$ & $78.66^{\circ} \mathrm{E}-110.33^{\circ} \mathrm{E}$ & $54.93^{\circ} \mathrm{S}-54.93^{\circ} \mathrm{N}$ \\
\hline M3 & C11 & MEO & $2012 / 4 / 30$ & $180^{\circ} \mathrm{W}-180^{\circ} \mathrm{E}$ & $55.31^{\circ} \mathrm{S}-54.61^{\circ} \mathrm{N}$ \\
\hline M4 & C12 & MEO & $2012 / 4 / 30$ & $180^{\circ} \mathrm{W}-180^{\circ} \mathrm{E}$ & $55.25^{\circ} \mathrm{S}-54.81^{\circ} \mathrm{N}$ \\
\hline M5 & C13 & MEO & $2012 / 9 / 19$ & $180^{\circ} \mathrm{W}-180^{\circ} \mathrm{E}$ & $54.99^{\circ} \mathrm{S}-56.02^{\circ} \mathrm{N}$ \\
\hline M6 & C14 & MEO & $2012 / 9 / 19$ & $180^{\circ} \mathrm{W}-180^{\circ} \mathrm{E}$ & $55.10^{\circ} \mathrm{S}-59.93^{\circ} \mathrm{N}$ \\
\hline
\end{tabular}

Figure 1 - Constellation of BeiDou-2 at the end of first phase of the projection. Satellites named C1, C2, C3, C4, and C5 are GEO satellites, with the yellow, blue, green, purple, red points, respectively. Satellites named C6, C7, C8, C9 and C10 are

IGSO satellites, with the red, yellow, purple, cyan and black sharps of "8", respectively. Satellites named C11, C12, C13 and C14 are the MEO satellites, with

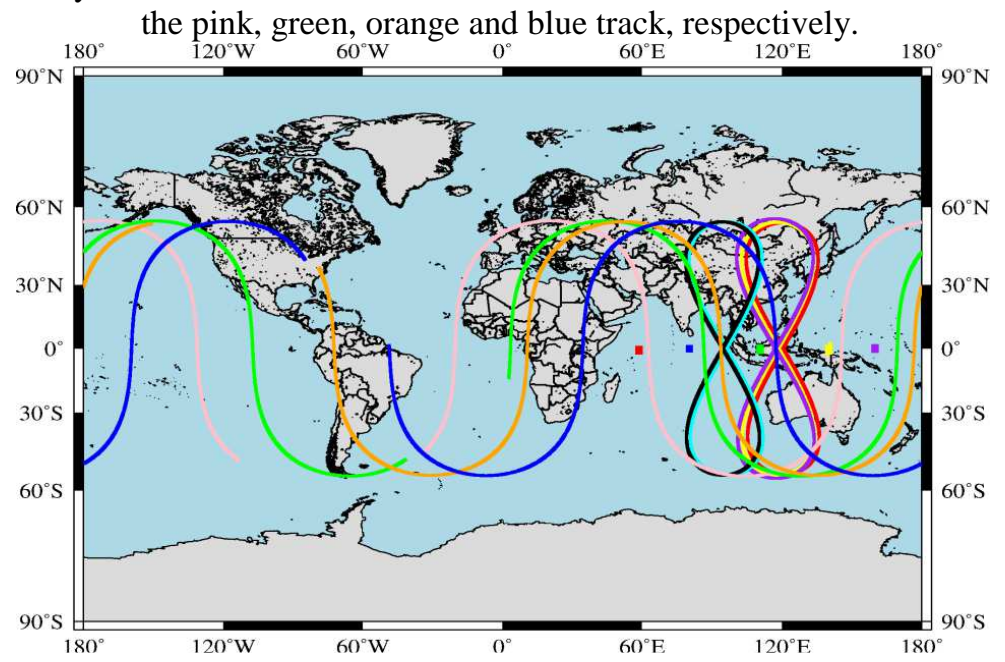

Bol. Ciênc. Geod., sec. Artigos, Curitiba, v. 20, no 2, p.223-236, abr-jun, 2014. 
The first phase BDS capacity of coverage for positioning is the Asian-Pacific region. Users in regions other than Asia-Pacificor neighbored area could not be benefitted from BeiDou-2 positioning service, due to only 4 BDS's MEO satellites operation. The second phase will complete the constellation, which consists of 5 GEO, 3 IGSO, 27 MEO satellites. The coverage will be expanded to a global scale. The MEO satellites could improve visibility, and will provide the navigation and positioning service for the global users, like GPS, GLONASS and Galileo. GEO and IGSO satellites will augment the visibility over the Asia-Pacific region. Furthermore, providing the backward compatibility with BeiDou-1 is also under considering (SHI et al. 2012).

BDShas its own coordinate reference system known as Chinese Geodetic Coordinate System 2000 (CGCS 2000) which consistency of the coordinate system is about $3 \mathrm{~cm}$ with respect to International Terrestrial Reference Frame 1997 (ITRF 1997) (CHEN 2008; SHI et al. 2012). BeiDou-2 time system (BDT) starts from coordinated Universal Time (UTC) 00:00:00, January 1, 2006. Difference between BDT and GPST is 14 seconds, i.e. BDT $=$ GPST $-14 \mathrm{~s}$. BeiDou-2's signals have been transmitted on three frequencies centered at 1,561.098 MHz (B1), 1,207.14 $\mathrm{MHz}$ (B2) and 1,268.52 MHz (B3), respectively.

Since the first satellite known as M1 was launched,some researches have been done in order to assess the BDS satellite navigation system. The satellite's PRN code sequences were decoded and the signals were analyzed. The results shown that, the observed signals of the M1 were stronger than the GPS signals(GAO et al. 2009; GRELIER et al. 2007a). The observations of M1 were comprehensive analyzed with its orbit and clock determination, the orbit is computed from laser ranging measurements(HAUSCHILD et al. 2011). Montenbruck et al.(2012)have assessed the performance of BeiDou- 2 and the quality of signal and measurements. There are also some researches based on simulated BDS measurements, e.g. Grelier et al. (2007b) analyze the satellite visibility and Position Dilution of Precision (PDOP). The results based on the simulation reveals that, the average of PDOP was less than 1.4 in China and neighboring regions, however 2.2 in America, Antarctic and Arctic regions. Shi et al. (2012) used both pseudo-range and phase measurements to estimate short baseline, and the precision of short baseline estimated by standalone BDS was better than $2 \mathrm{~cm}$ for the North component and 4 $\mathrm{cm}$ for the vertical. The standard deviation of the east component is smaller than 1 $\mathrm{cm}$.

All the above researches accomplished during the process of BDS deployis hard to assess the BDS system objectively and overall. At the end of first phase BDS, it is necessary to analyze the performance of BDS. In the second section, measurements were collected in two stations equipped with GPS/BDS's receivers during a whole BDS orbital period in Shanghai, China. In this section, equipment and experiment were described briefly. In the third section, BDS satellites' visibility and tracked time are analyzed, comparing with GPS. Multipath combinations are presented and analyzed the precision of pseudo-range measurements. Geometric 
Dilution Of Precision (GDOP), Horizontal Dilution Of Precision (HDOP) and Vertical Dilution Of Precision (VDOP) of GPS and BDS are also analyzed over a whole day observations. In the fourth section, in order to assess the performance of static short baseline estimation, the two stations are segmented into 48 segmentations with 30 minutes observations. The short baseline could be estimated by each segmentations standalone GPS (L1) and BDS (B1) carrier phase measurements, respectively. Furthermore, double differenced carrier phase observations with the ambiguities fixed under the constraint of precise short baseline are used to produce the kinematic positioning epoch by epoch.

\section{FIELD EXPERIMENT}

ComNav GPS/BDS receiver board (ComNav-K503), commercial receiver (ComNav-M300C) and two antenna supported by GPS/BDS are used in this field experiment. Dual-frequency phase, pseudo-range measurements (modulated on signal B1, B2, L1 and L2) and $\mathrm{C} / \mathrm{N}_{\mathrm{o}}$ are collected from UTC 00:00:00 to 23:59:59 on 28 December, 2012. The sampling intervals and mask-off elevation for the two receivers were set as 1 second and $15^{\circ}$, respectively. This experiment was carried out on the roof of building in ComNav Company, Shanghai, China (Figure 2), and the baseline is about 126 meters.

Figure 2 - ComNav GPS/BDS receiver board connected with antenna A (left couple), ComNav GPS/BDS receiver connected with antenna B (right couple).
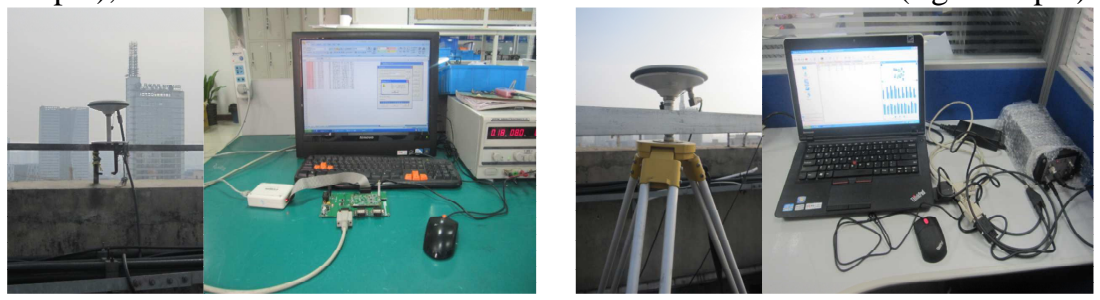

\section{ASSESSMENT OF BDS SATELLITES VISIBILITY AND QUALITY OF OBSERVATIONS}

In this section, satellite visibility and time that available satellites could be tracked are considering to analysis the performance of BDS constellation. Multipath combination observations are used to analyze the quality of pseudo-range measurements. Furthermore, DOP time series which reveal the relationship between receiver and satellite are also analyzed.

\subsection{Visibility and Tracked Timeof Available GPS and BDS Satellites}

We use the real BDS navigation file and simulate one observer in Equatorial region (Padang, Indonesia) and another observer is in Beijing, China, with the 
coordinate as (X: -1149077.8879m; Y: 6227881.8470m; Z: -115065.9575m) and (X: -2169528.4733m; Y: 4385268.3297m; Z: 4078214.6302m), respectively.

Figure 3 (A) shows that, all the GEO and IGSO satellites could be tracked with the elevation angle above 22.5 degree in Padang, Indonesia. BDS MEO satellites could be tracked over a certain time-arc of their orbital period, like GPS and Glonass. The performance of BDS visibility in high latitude region, e.g. Beijing, is worse than in subequatorial region (Figure $3 \mathrm{~B}$ ). BDS IGSO satellites could be outsight during the whole orbital period, comparing to the whole IGSO orbital period could be tracked in subequatorial region.

Figure 3 - GEO, IGSO, MEO of BDS satellites' track view in Equatorial region (A) and Beijing (B), respectively.

A

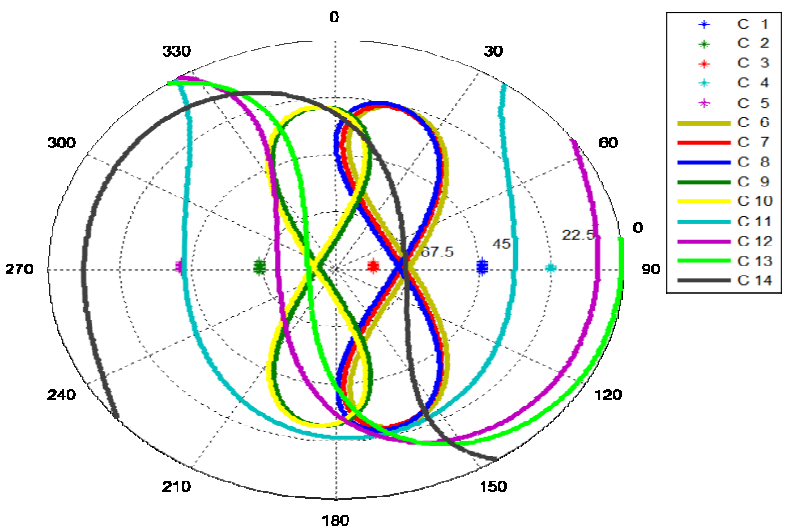

B

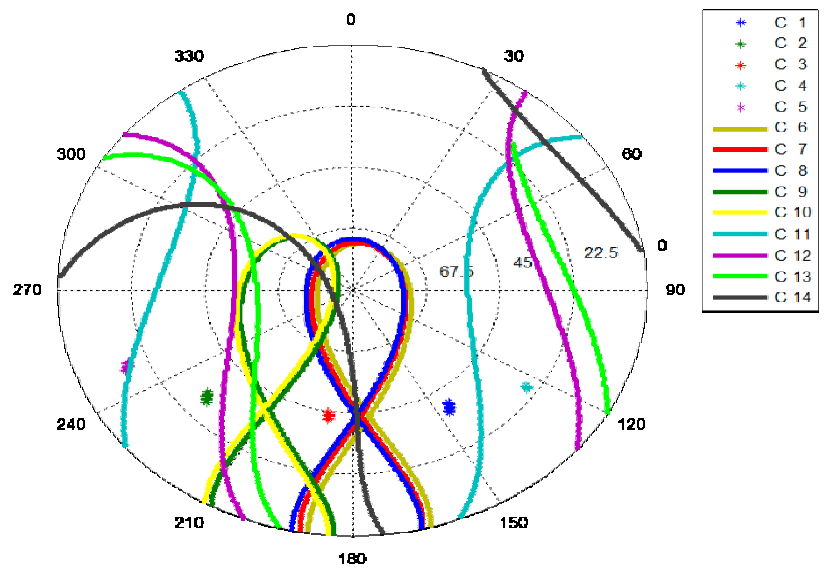


Result based on the real data collected in Shanghai, showsthat moreBDS satellites could be tracked during a whole BDS orbital period (about 24 sidereal hours), comparing to GPS with the mask-off elevation angle setting at 15 degree (Figure 4 top). Even though the mask off elevation angle is set as 30 degree, BDS still has the capacity of navigation and positioning (at least 6 BDS satellite visible, Figure 4 bottom).

Figure 4 - Number of BDS and GPS satellites could be tracked as elevation cutoff mask of $15^{\circ}$ (top) and $30^{\circ}$ (bottom).

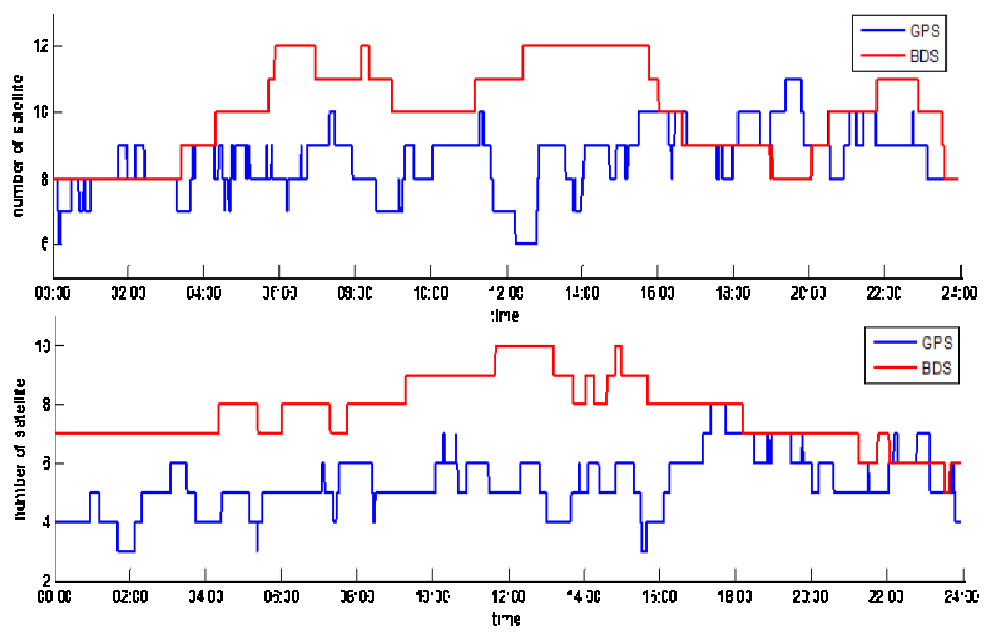

Figure 5 - Duration of GPS and BDS each satellite could be tracked in Shanghai, China, during 00:00:00 to 23:59:59on December 28, 2012.01 to 05 (red) are BDS GEO satellites, 06 to 10 (red) are BDS IGSO satellites, 11 to 14 (red) are BDS MEO satellites. 01 to 32 (green) are GPS MEO satellites.

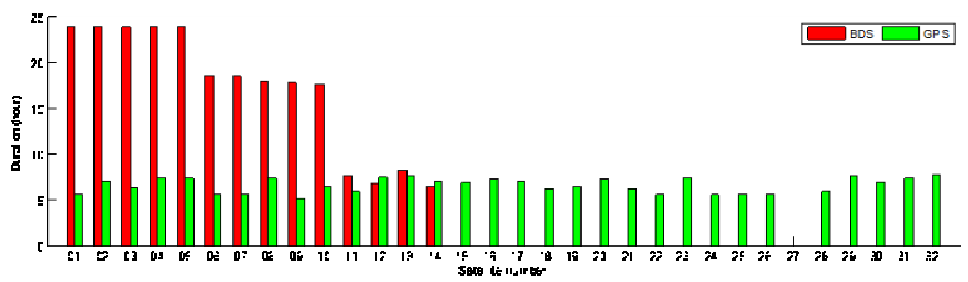

Tracked time of satellites is definedas how many hours satellites could be tracked during the whole orbital period. Figure 5 shows the hours of BDS and GPS satellites tracked during a whole BDS orbital period, in Shanghai, on 28 December, 2012. During the whole BDS orbital period ( 24 hours, about 2 times of GPS orbital 
period), BDS MEO satellites are always available. More than 17 hours, all BDS IGSO satellites' signal could be tracked. The tracked time of BDS MEO satellites is similar with GPS ones, the duration is around 5 hours. From Fig. 5, tracked time of BDS GEO and IGSO satellites is better than BDS MEO and GPS satellites in AsiaPacific regions. It should be mentioned that, BDS GEO and IGSO satellites' signal might not be locked other than Asia-Pacific and neighbored regions, due to the characteristic of their orbit.

\subsection{Observation Analysis}

Multipath combination observation reveal the level of multipath, receiver noise and the bias variations between pseudo-range and carrier phase observations. Due to BDS constellation consist of GEO, IGSO, and MEO satellites, we analyze measurements of C02 (GEO), C07 (IGSO) and C14 (MEO), respectively. The combination measurement could be got as following equations (Eq. 1):

With

$$
M P_{A}=P_{A}-(\alpha+1) \phi_{A}+\alpha \phi_{B}
$$

$$
\alpha=2 f_{B}^{2} /\left(f_{A}^{2}-f_{B}^{2}\right)
$$

Where, $M P_{A}$ denotes the multipath of signal $A . P_{A}$ is pseudo-range observations. $\phi_{A}$ and $\phi_{B}$ are the carrier phase observations of signal $A$ and signal $B$, respectively. $f_{A}$ and $f_{B}$ are the frequencies of signal $\mathrm{B} 1$ and $\mathrm{B} 2$, respectively.

The range of $\mathrm{C} 02$ elevation is from $31^{\circ}$ to $34^{\circ}$, and the multipath combination is in the range of 1 meter (Fig. 6 top). Multipath combinations of $\mathrm{C} 07$ and $\mathrm{C} 14$ are also plotted with the changing of satellites' elevation (Fig. 6 middle and bottom).

Result of $\mathrm{C} 07$ and $\mathrm{C} 14$ shows that, the variation of multipath combinations is more obvious when the satellites' elevation smaller than $30^{\circ}$.

\subsection{Dilution of Precision}

Position and time accuracy in the satellite navigation system are not only decided by the accuracy of observations from satellites to receivers, but also the GDOP. DOP reflects the geometry relationship between the receiver and visible GNSS satellites. We assume there are k satellites could be tracked at on epoch, so the coefficient of observation equation could be written as,

$$
Q_{q}=\left[\begin{array}{cccc}
l_{1} & m_{1} & n_{1} & 1 \\
l_{2} & m_{2} & n_{2} & 1 \\
l_{3} & m_{3} & n_{3} & 1 \\
& \ldots & & \\
l_{k} & m_{k} & n_{k} & 1
\end{array}\right]
$$

GDOP could be given as 
Xu Tang. et al.

$$
\begin{gathered}
\text { GDOP }=\sqrt{\operatorname{trace}\left[\left(Q_{\mathrm{q}}^{\mathrm{T}} \mathrm{Q}_{\mathrm{q}}\right)^{-1}\right]}=\sqrt{\sigma_{\mathrm{x}}^{2}+\sigma_{\mathrm{y}}^{2}+\sigma_{\mathrm{z}}^{2}+\sigma_{\mathrm{t}}^{2}}=\sqrt{\mathrm{PDOP}^{2}+\mathrm{TDOP}^{2}} \\
=\sqrt{\mathrm{HDOP}^{2}+\mathrm{VDOP}^{2}+\mathrm{TDOP}^{2}}
\end{gathered}
$$

Where, trace [-] is matrix trace function, $\sigma_{x}^{2}, \sigma_{y}^{2}, \sigma_{z}^{2}$ and $\sigma_{t}^{2}$ are the diagonally elements of the matrix $\left(Q_{q}^{T} Q_{q}\right)^{-1} . P D O P, H D O P, V D O P$ and TDOP could be written as,

$$
\begin{gathered}
P D O P=\sqrt{\sigma_{x}^{2}+\sigma_{y}^{2}+\sigma_{z}^{2}} \\
H D O P=\sqrt{\sigma_{x}^{2}+\sigma_{y}^{2}} \\
V D O P=\sqrt{\sigma_{h}^{2}} \\
T D O P=\sqrt{\sigma_{t}^{2}}
\end{gathered}
$$

Figure 7 A-C shows the GDOP, HDOP and VDOP of GPS and BDS during a whole BDS orbital period for the GPS/BDS receiver (ComNav-M300C). The standard deviations of BDS's and GPS's GDOP are 0.427 and 0.442 , respectively. However, BDS GDOP performs better than GPS. Performance of BDS's HDOP is better than GPS's, but opposite on VDOP, due to the BDS and GPS constellation are different (Figure $7 \mathrm{~B}, \mathrm{C}$ ). Most of the time, BDS HDOP is smaller than GPS during 24 hours (BDS orbital period) except for few epochs.

Figure 6 - Multipath combination of C02 (GEO), C07 (IGSO) and C14 (MEO) for pseudo-range on signal B1.
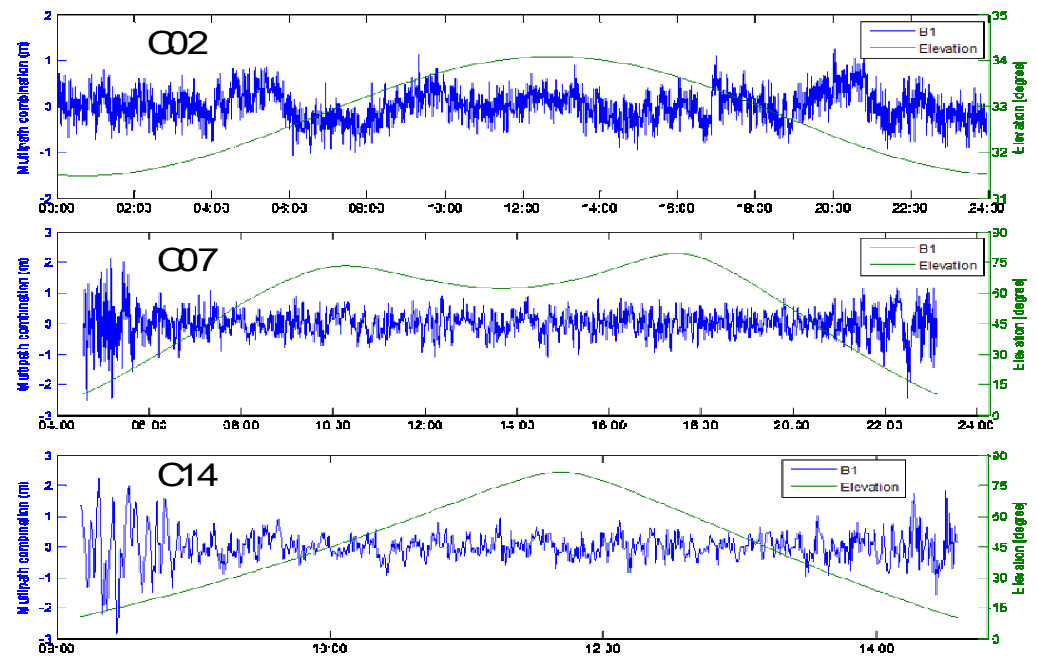

Bol. Ciênc. Geod., sec. Artigos, Curitiba, v. 20, nº 2, p.223-236, abr-jun, 2014. 
Figure. 7 - GPS and BDS dilution of precision (DOP) during a whole BDS orbital period.

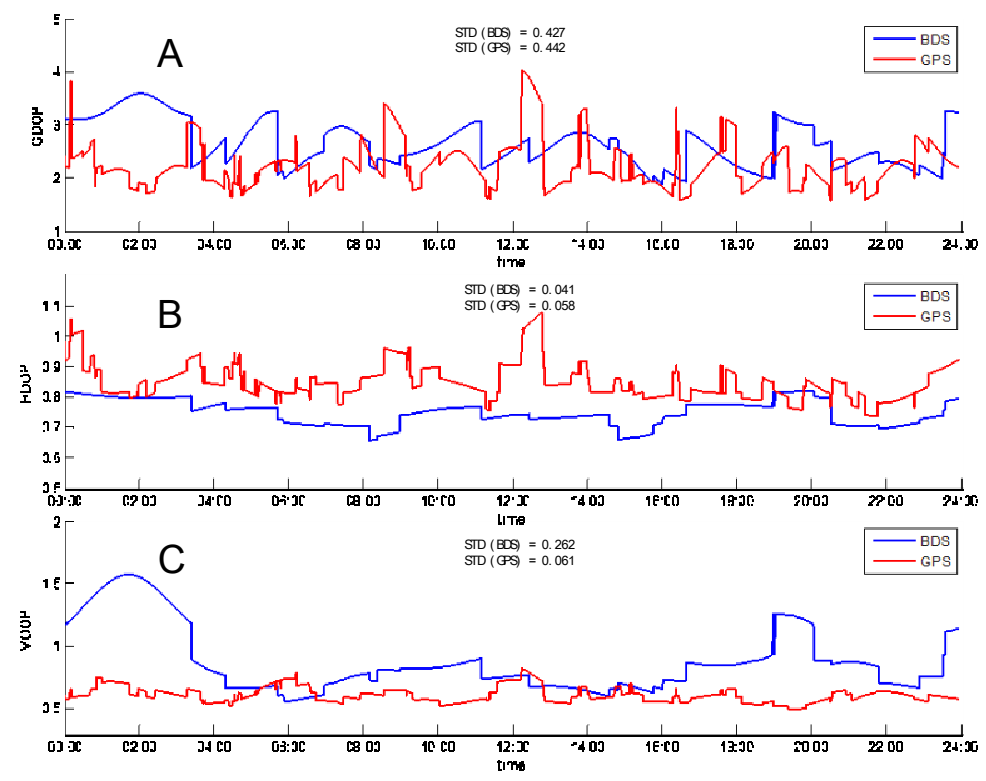

\section{STANDALONE BDS HIGH PRECISE RELATIVEPOSITIONING}

In former sections, satellites visibility and BDS DOP are analyzed.Tracked time of Different type BDS satellites also listed. The results demonstrate that, BDS GEO and IGSO could be tracked longer than BDS MEO and GPS satellites in AsiaPacific and neighboring areas. In this section, static relative positioning is analyzed by estimating the precise short baseline usage 48 segmented observations. Kinematic results are gained by the double differenced B1 (L1) carrier phase measurements with the ambiguity fixed under constraint of precise short baseline vector.

\subsection{Static Relative Positioning}

The data collected from two GPS/BDS dual frequency receivers are used to collect observations for a whole day (section 2, Field experiment). All BDS satellites (including 5 GEO, 5 IGSO, 4 MEO satellites) could be tracked, and its phase observations are available. An automated cycle slip detection and repair method developed by Liu(2010)and Cai et al. (2012)is used to pre-process the BDS and GPS carrier phase measurements.This method use Melbourne-Wübbena wide lane (MWWL) and the ionospheric total electron contents rate (TECR), jointly, to detect and repair cycle slip, due to these two method have their own shortcomings.Many cases of cycle slips on carrier phase L1, L2 and B1, B2 could 
be successful solved (Liu 2010).Short baseline about 126 meters is estimated by standalone GPS and BDS's double differenced carrier phase measurements with the ambiguity fixed by LAMBDA, respectively.

Figure 8 - Components of short baseline estimated by GPS and BDS, respectively (28 December, 2012).
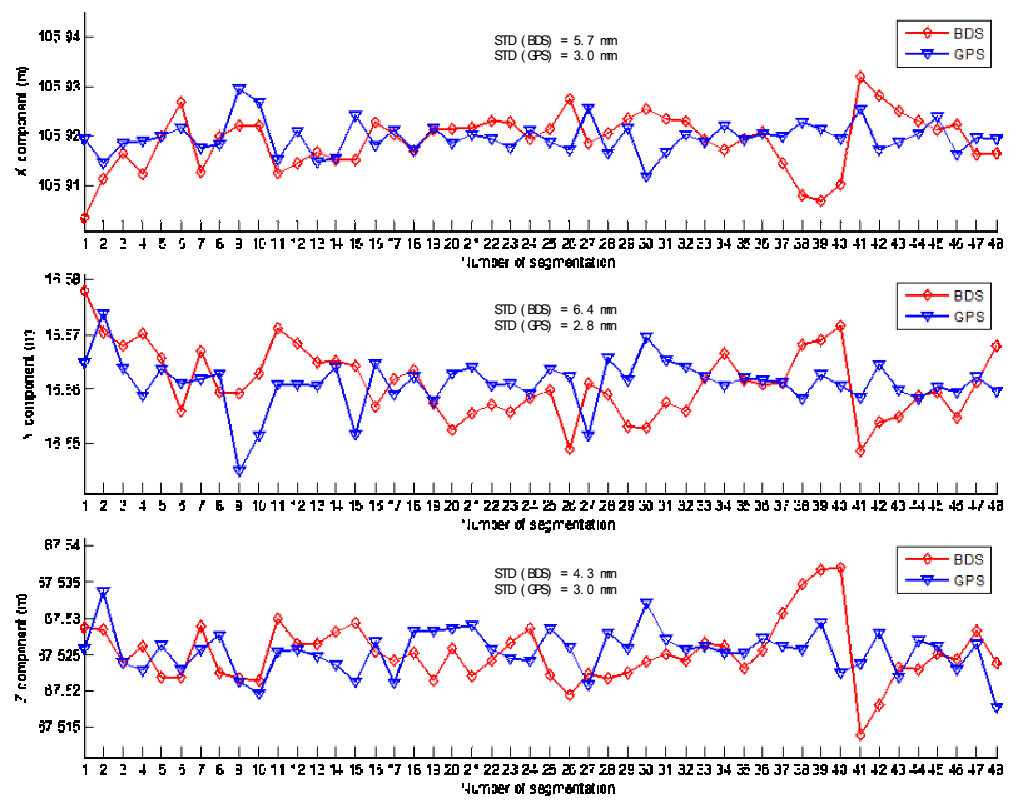

Due to GPS has been widely used in many field and applications, the baseline estimated by GPS could be thought as stable and authoritative. Figure 8 shows that short baseline on $\mathrm{X}, \mathrm{Y}$ and $\mathrm{Z}$ component estimated by BDS are worse than GPS results. Standard deviation of BDS X and $Y$ components are $5.7 \mathrm{~mm}$ and $6.4 \mathrm{~mm}$, respectively, around 2 times of GPS X $(3.0 \mathrm{~mm})$ and Y components $(2.8 \mathrm{~mm})$.

Figure 9 - Short baseline estimated by GPS and BDS respectively (28 December, 2012).

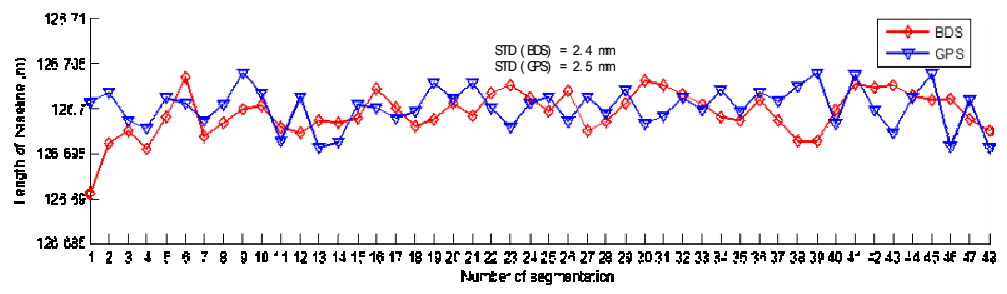

Bol. Ciênc. Geod., sec. Artigos, Curitiba, v. 20, nº 2, p.223-236, abr-jun, 2014. 
Figure 9 gives the length of baseline estimated by GPS and BDS standalone observations. Standard deviation of short baseline length estimated by BDS observationsis $2.4 \mathrm{~mm}$, corresponding to the GPS's $2.5 \mathrm{~mm}$. Millimeters level of baseline is available to be estimated by BDS carrier phase measurement with the ambiguity fixed.

\subsection{Kinematic Relative Positioning}

We denotethe ComNav GPS/BDS receiver board (ComNav-K503) and commercial receiver (ComNav-M300C) as receiver A and B, respectively. The position of $\mathrm{A}$ could be computed by the pseudo-range measurements with low precision. The high precise relative position between receiver A and B are estimated by a whole day standalone GPS and BDS observations, in the section static relative positioning. The errors of satellites and ground receivers could be eliminated by double differencedmethod. The troposphere and ionosphere delays are also significantly reduced due to the delays strong regional correlation (Xu, 2007). With the constrain condition of precise relative position, ambiguity could be gained at each epoch. The only unknown parameter is the baseline vector could be estimated epoch by epoch. Position accuracy of time series reveals the carrier phase measurements' accuracy.

Figure 10 - Kinematic baseline solutions using standalone b1 and 11 double differenced carrier phase measurements.
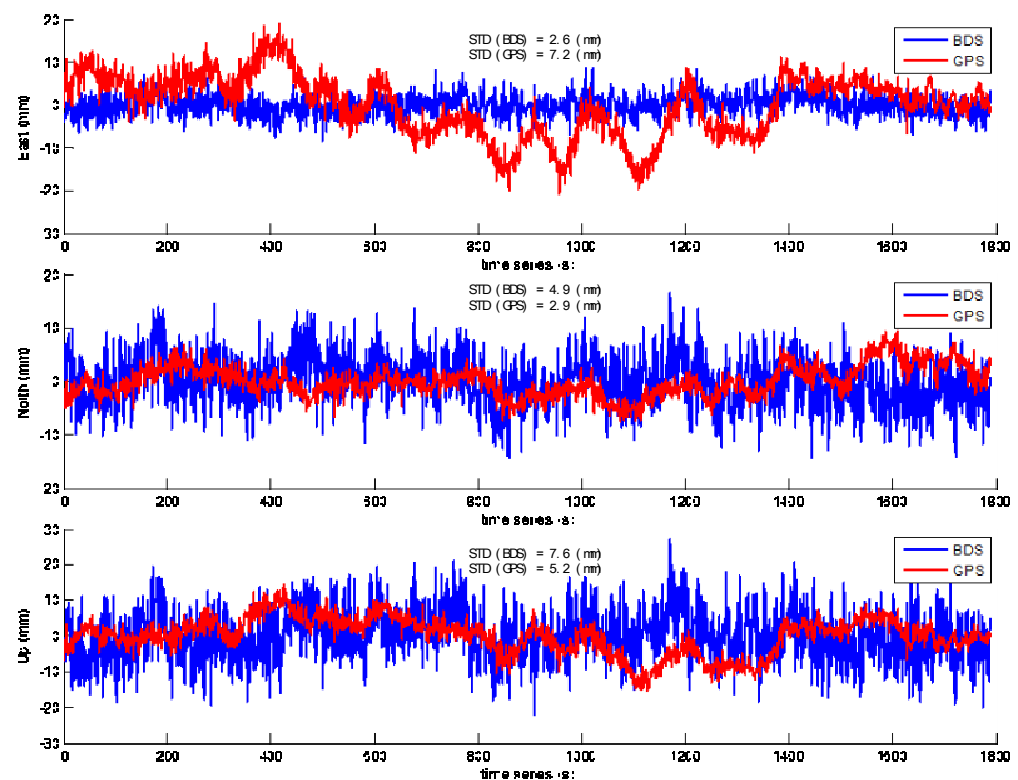

Bol. Ciênc. Geod., sec. Artigos, Curitiba, v. 20, no 2, p.223-236, abr-jun, 2014. 
Figure 10 shows the time series of epoch by epoch errors in three components with respect to the "true baseline vector" which is estimated by static relative positioning technology using 24 hours GPS and BDS observations. The solutions are produced by standalone GPS L1 and BDS B1 carrier phase measurements, respectively. Results on East, North and Up component could achieve level of centimeter with $2 \mathrm{~cm}$ errors. BDS East component performs better than GPS (STD of GPS is $7.2 \mathrm{~mm}$; STD of BDS is $2.6 \mathrm{~mm}$ ). Oppositely, the performance of GPS is better than BDS on North and Up components.

\section{CONCLUSIONS}

In this paper, we collected the real data to assess the constellation of BDS satellite navigation system, since the first phase of BDS was completed at the end of 2012. The tracked durationof GPS and BDS satellites are analyzed during a whole BDS orbital period (24 hours). The results show that, BDS GEO and IGSO satellites could be tracked longer than BDS MEO and GPS satellites. Tracked time of BDS MEO satellites perform similar with GPS ones(all BDS MEO and GPS satellites could be tracked around 5 to 7 hours during 24 hours). It is necessary to note that, BDS GEO and IGSO satellites are unavailable in the region other than AsiaPacificand neighboring area, due to its orbit characteristic. More BDS satellites are available during 24 hours, comparing to GPS observations in Shanghai, China.

Multipath combinationsof $\mathrm{C} 2, \mathrm{C} 7$ and C14representing BDSGEO, IGSO and MEO satellites are also analyzed and the results show that, errors increase sharply when the satellites' elevation less than 30 degree.

Series of BDS DOP are calculated by using the real data collected by GPS/BDS receiver (ComNav-M300C) which is fixed on the roof of Shanghai ComNav Company building. Comparing with GPS results, GDOP of GPS is slightly better than that of BDS. Performance of BDS HDOP is better than GPS, but opposite on VDOP, Most of BDS HDOP smaller than GPS except few epochs during 24 hours.

A short baseline estimated by standalone BDS and GPS carrier phase measurements, respectively. Standard deviation of short baseline on $\mathrm{X}, \mathrm{Y}$ and $\mathrm{Z}$ components obtained from GPS is better than BDS. Standard deviation of short baseline length obtained from BDS is slightly better than GPS.

The kinematic baseline solutions using standalone BDS and GPS carrier phase measurements demonstrate that the precision of BDS solutions' East performance is better than that of GPS. BDS solutions' North and Up components perform worse than that of GPS.

It should be noted that all the results are obtained in this paper based on the first phase of BDS completely constellation (5 GEO, 5 IGSO and 4 MEO satellites). The BDS satellite navigation system is still improving and will contain 5 GEO, 3 IGSO and 27 MEO satellites at the end of 2020. The coverage will be expanded for 
Asia-pacific region to global scale at that time. In GNSS community, there are more satellites and more signals with different frequency are available.

\section{ACKNOWLEDGEMENT}

The research of the author has been supported by the Scientific Research Foundation forNASG Key Laboratory of Land Environment and Disaster Monitoring (No. LEDM2012B06). Authors would like to thank Vagner G. Ferreira for his assistance and he gave a lot of effective suggestions and Lili Chan, Fei Ma from ComNav Company to share the BDS/GPS observation files.

\section{REFERENCE}

CAI C, LIU Z, XIA P, DAI W. Cycle slip detection and repair for undifferenced GPS observations under high ionospheric activity. GPS Solutions. 2012. doi: 10.1007/s10291-012-0275-7.

CAO C, JING G, LUO M. COMPASS Satellite Navigation System Development. PNT Challenges and Opportunities Symposium, Stanford, California, USA 133, 2008.

CHEN J. Chinese Modern Geodetic Datum: Chinese Geodetic Coordinate System 2000 (CGCS 2000) and its Frame. Acta Geodaetica et Cartographica Sinica 37:6-8, 2008.

GAO G, CHEN A, LO S. Compass-M1 broadcast codes in E2, E5b, and E6 frequency bands. IEEE Journal of Selected Topics in Signal Processing 3:599612, 2009.

GRELIER T, DANTEPAL J, DELATOUR A,. Initial observations and analysis of compass MEO satellite signals. Inside GNSS 39-42, 2007a.

GRELIER T, GHION A, DANTEPAL J. Compass signal structure and first measurements. The Institute of Navigation Global Navigation Satellite System 3015, 2007b.

HAUSCHILD A, MONTENBRUCK O, SLEEWAEGEN J-M. Characterization of Compass M-1 signals. GPS Solutions 16:117-126, 2011. doi: 10.1007/s10291011-0210-3

LIU Z. A new automated cycle slip detection and repair method for a single dualfrequency GPS receiver. Journal of Geodesy 85:171-183, 2010. doi: 10.1007/s00190-010-0426-y

MONTENBRUCK O, HAUSCHILD A, STEIGENBERGER Pl. Initial assessment of the COMPASS/BeiDou-2 regional navigation satellite system. GPS Solutions. 2012. doi: 10.1007/s10291-012-0272-x

SHI C, ZHAO Q, HU Z, LIU J. Precise relative positioning using real tracking data from COMPASS GEO and IGSO satellites. GPS Solutions 17:103-119, 2012. doi: 10.1007/s10291-012-0264-x

XU, G. GPS Theory, Algorithms and Applications. (Second Edi.). Springer Berlin Heidelberg New York 107-110, 2007.

(Recebido em julho de 2013. Aceito em dezembro de 2013). 